\title{
EDITORIAL
}

Adv Clin Exp Med 2014, 23, 1, 5-7

ISSN 1899-5276

๑ Copyright by Wroclaw Medical University

Yasin Al-Qubati ${ }^{\text {A, B, E, F, Edmund J. Janniger }}{ }^{\mathrm{C}, \text { D }}$, Robert A. Schwartz ${ }^{\mathrm{C}, \text { E, F }}$

Pyogenic Granuloma of the Lip - Treatment with Carbon Dioxide Slush Cryosurgery as an Approach in a Resource-Poor Country

Dermatology, Taiz University School of Medicine, Taiz, Yemen and Dermatology and Pediatrics, Rutgers University New Jersey Medical School, Newark, New Jersey, USA

A - research concept and design; $\mathbf{B}$ - collection and/or assembly of data; $\mathbf{C}$ - data analysis and interpretation;

$\mathbf{D}$ - writing the article; $\mathbf{E}$ - critical revision of the article; $\mathbf{F}$ - final approval of article; $\mathbf{G}$ - other

\begin{abstract}
Pyogenic granuloma (PG) is a benign vascular neoplasm most often evident as a rapidly developing solitary, sessile, or polypoid vascular nodule or tumor prone to ulceration or hemorrhage. Bleeding may be episodic, copious, and refractory to pressure, mandating treatment, particularly when on the lip. We describe a 14-year-old adolescent with a PG of the lower lip that responded to carbon dioxide slush cryosurgery, an option that may be of considerable value in a resource-poor country (Adv Clin Exp Med 2014, 23, 1, 5-7).
\end{abstract}

Key words: pyogenic granuloma, vascular neoplasm, cryosurgery, Yemen.

Pyogenic granuloma (PG) is a benign vascular neoplasm of the skin and sometimes mucous membranes that is common in infancy and childhood [1]. It is usually observed as a rapidly developing solitary, sessile, or polypoid vascular nodule or tumor prone to ulceration or hemorrhage [1-5]. Bleeding may be episodic, copious, and refractory to pressure, thus requiring treatment, particularly when on the lip. There are many therapeutic options, one of which is cryosurgery $[1-3,5]$. We describe a 14-year-old adolescent with a PG of the lower lip that responded to carbon dioxide slush cryosurgery, an option that may be of considerable value in a resource-poor country. This technique was adapted from what was originally specially tailored for cutaneous leishmaniasis [6].

\section{Report of a Case}

A 14-year-old adolescent was seen with a nodule on the lower lip of three months duration. It was enlarging and frequently bled, especially with repeated minor trauma while eating or playing with his peers. Because of recurrent bleeding, his parents became greatly concerned, so his father brought him to the private clinic of one of us (YA-Q) to remove the nodule. The patient related its onset to biting his lip during football matches.

On examination, the healthy-appearing young man had a painless bright red crusted nodule with a glistening surface $1.4 \mathrm{~cm}$ in diameter on the lip (Fig. 1, 2). After discussion, he was treated with a carbon dioxide snow cautery. This carbon dioxide gas was obtained from a nearby soft drink factory utilizing a big cylinder. While pressing the outlet with a towel, the escaping gas met resistance and changed into solid slush. A broken plastic syringe

This work was presented in part at the 22nd World Congress of Dermatology: Al-Qubati Y, Janniger EJ, Schwartz RA, Pyogenic granuloma of the lip. Treatment with carbon dioxide slush cryosurgery. 22nd World Congress of Dermatology Abstract No. P1785, Seoul, Korea 2011. 


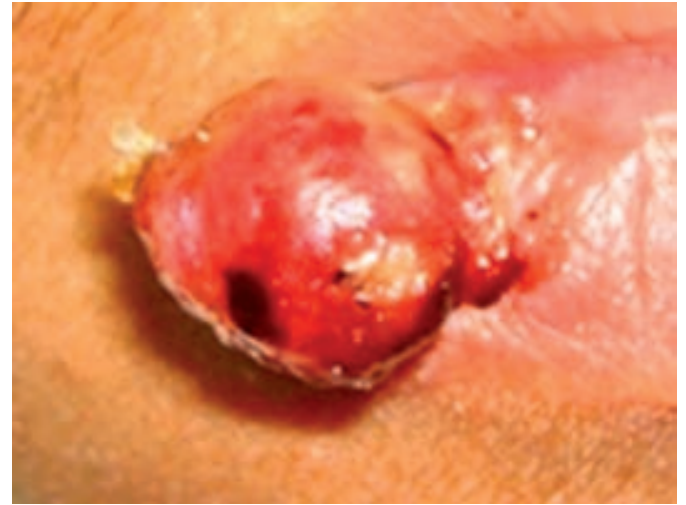

Fig. 1. Fourteen-year-old child with pyogenic granuloma of the lip, a nodule with a glistening surface

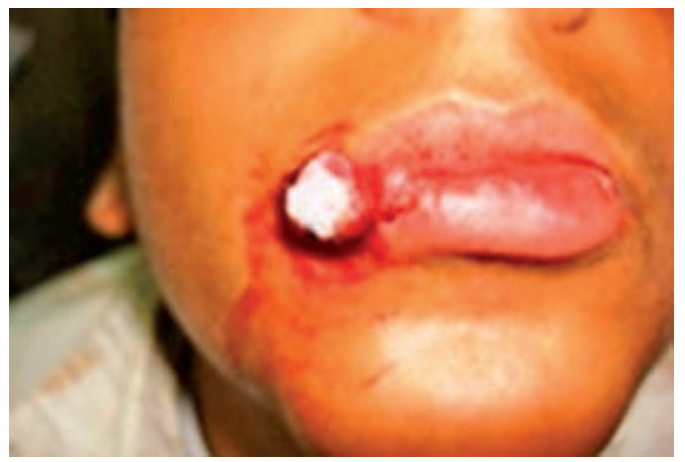

Fig. 2. White area of nodule denotes site of cryosurgery

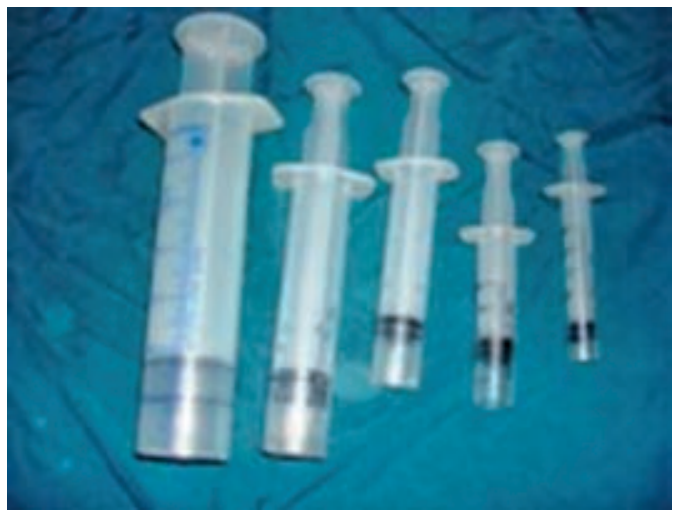

Fig. 3. Multiple syringes adapted for this technique according to the size of the lesion, specially tailored for cutaneous leishmaniasis and adapted for this pyogenic granuloma

was filled with the $\mathrm{CO}_{2}$ snow (Fig. 3). This cautery with carbon dioxide slush was continued for $1 \mathrm{~min}$, and stopped until the nodule warmed again. Then application of this cryogen was commenced again for 1 more min. This procedure was repeated every other day until the nodule completely disappeared (Fig. 4). There was some pain during application due to the low temperature of the $\mathrm{CO}_{2}$ snow, but the patient tolerated it well. The patient

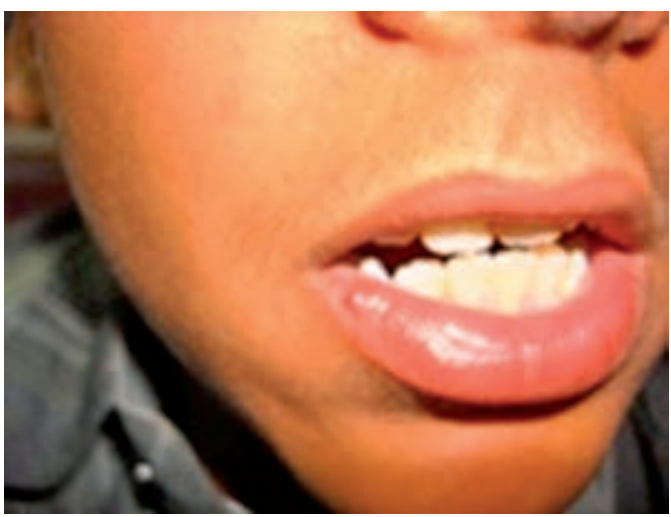

Fig. 4. Normal appearing lip after carbon dioxide slush cryotherapy for pyogenic granuloma

was advised to use fucidic acid topical cream on the lesion twice daily after each treatment session.

\section{Discussion}

We describe a child with pyogenic granuloma of the lip, a relatively common neoplasm. It was named to describe what in 1906 was believed to be an infectious disorder marked by granulomatous inflammation $[1,7]$. The term "lobular capillary hemangioma" may better reflect its vascular proliferations that often appear histologically organized into lobules. PG is linked in some patients with localized trauma, which may play a major role in its pathogenesis [8-10]. Amazingly, PG has been described as a complication of cryosurgery on the vermillion border for a venous lake, and in other sites $[11,12]$. A hormonal role has also been postulated when PG occurs on the gingival surface during pregnancy or with the use of oral contraceptives [13]. In children, most occur within the first 5 years of life with a frequency that appears to decrease linearly with age [5]. The solitary variant of pyogenic granuloma is relatively common in children, representing $0.5 \%$ of all skin nodules in children [14].

The pyogenic granuloma in our patient was a typical solitary one arising as a painless bright red crusted or ulcerated nodule with a glistening surface on the lower lip. Over the course of several weeks, it rapidly proliferated, growing in size from a few $\mathrm{mm}$ to several $\mathrm{cm}$ with frequent bleeding after minor trauma. Lips and mucosal membranes such as gingiva, buccal mucosa, nasal mucosa and laryngeal mucosa are also common sites, as in our patient [15-17]. In our differential diagnosis, we were most concerned about other neoplasms, in particular melanoma and bacillary angiomatosis, both of which may resemble a PG [18-20]. We have had a pediatric patient with an apparent PG on the 
earlobe which did not respond to cryosurgery. Histologically, it was a melanoma. Similarly, we have had a few immunocompromised patients in whom the clinical and histological diagnosis was a PG. Reevaluation of the histological specimen showed the correct diagnosis was bacillary angiomatosis.

There are many therapeutic options. In Yemen, a resource-poor country, we utilized carbon dioxide snow cryosurgery, as described within this report. In this way the cost of the therapy itself to the patient was only about $\$ 20$ US. We recommend this form of cryosurgery be considered for the treatment of PG, particularly where available in resource-poor countries.

\section{References}

[1] Lin RL, Janniger CK: Pyogenic granuloma. Cutis 2004, 74, 229-233.

[2] Ghodsi SZ, Raziei M, Taheri A, Karami M, Mansoori P, Farnaghi F: Comparison of cryotherapy and curettage for the treatment of pyogenic granuloma: a randomized trial. Br J Dermatol 2006, 154, 671-675.

[3] Edalatkhah H, Mohebbipoor AR, Egtedari F: Comparison of cryosurgery and electrocautery in pyogenic granuloma. Iranian J Dermatol 2006, 9, 127-131.

[4] Patrice SJ, Wiss K, Mulliken JB: Pyogenic granuloma (lobular capillary hemangioma): a clinicopathologic study of 178 cases. Pediatr Dermatol 1991, 8, 267-276.

[5] Kuflik EG: Cryosurgery updated. J Am Acad Dermatol 1994, 31, 925-944, quiz 944-946.

[6] Al-Qubati Y, Janniger EJ, Schwartz RA: Old World cutaneous leishmaniasis: cryosurgery using carbon dioxide slush in a resource-poor country. Int J Dermatol 2012, 5, 1217-1220.

[7] Hartzell MB: Granuloma pyogenicum (Botryomycosis of French authors.) J Cutan Dis 1904, 22, 520-525.

[8] Michelson HE: Granuloma pyogenicum: a clinical and histologic review of twenty-nine cases. Arch Dermatol Syphil 1925, 12, 492-505.

[9] Davies MG, Barton SP, Atai F, Marks R: The abnormal dermis in pyogenic granuloma: Histochemical and ultrastructural observations. J Am Acad Dermatol 1980, 2, 132-142.

[10] Kumar Ghosh S, Bandyopadhyay D: Granuloma pyogenicum as a complication of decorative nose piercing: report of eight cases from eastern India. J Cutan Med Surg. 2012, 16, 197-200.

[11] Cecchi R, Giomi A: Pyogenic granuloma as a complication of cryosurgery for venous lake. Br J Dermatol 1999, 140, 373-374.

[12] Elton RF: Complications of cutaneous cryosurgery. J Am Acad Dermatol 1983, 8, 513-519.

[13] Rader C, Piorkowski J, Bass DM, Babigian A: Epulis gravidarum manum: pyogenic granuloma of the hand occurring in pregnant women. J Hand Surg Am 2008, 33, 263-513.

[14] Grimalt R, Caputo R: Symmetric pyogenic granuloma. J Am Acad Dermatol 1993, 29, 652.

[15] da Nova Cruz LE, Martos J: Granuloma gravidarum (pyogenic granuloma) treated with periodontal plastic surgery. Int J Gynaecol Obstet 2010, 109, 73-74.

[16] Lawoyin JO, Lawoyin DO, Arowojolu MO, Lawoyin T, Akande OO: Prevalence of pregnancy related oral granuloma in a Nigerian population group and the possible role of contraceptives. Afr J Med Med Sci 2003, 32, 409-412.

[17] Saravana GH: Oral pyogenic granuloma: a review of 137 cases. Br J Oral Maxillofac Surg. 2009, 47, 318-319.

[18] Schwartz RA, Nychay SG, Janniger CK, Lambert WC: Bacillary angiomatosis: presentation of six cases, some with unusual features. Br J Dermatol 1997, 136, 60-65.

[19] Elmets CA, Ceilley RI: Amelanotic melanoma presenting as a pyogenic granuloma. Cutis 1980, 25, 164-168.

[20] Cohen PJ, Hoffmann MA, Sterry W, Schwartz RA: Melanoma. In: Skin Cancer: Recognition and Management. Ed.: Blackwell, Oxford, United Kingdom, 2008, $2^{\text {nd }}$ ed., 152-199.

\section{Address for correspondence:}

Yasin Al-Qubati

Dermatology, Taiz University School of Medicine

P.O. Box 6330, Taiz

Yemen

E-mail: alkobati@yahoo.com

Conflict of interest: None declared

Received: 20.07.2013

Accepted: 20.02.2014 